\title{
Marco Thomas Bosshard \\ Warisata en el arte, la literatura y la política boliviana. Observaciones acerca del impacto de la Escuela Ayllu en la producción artística boliviana y la nueva legislación educativa del gobierno de Evo Morales
}

\section{Advertencia}

El presente artículo -si bien respeta la forma, las convenciones y las metodologías de nuestra disciplina- va más allá de un ensayo de crítica literaria pues examina y comenta la política boliviana actual. Por tanto, éste no es un texto acabado sino todo lo contrario: se trata de un texto "abierto" que requiere continuación y, tal vez, corrección por parte de sus lectores. Sin embargo, lejos de provocar polémicas, espero que algunas de mis observaciones puedan contribuir a un debate serio -es decir, sin prejuicios- sobre las oportunidades, pero también los peligros, de la política contemporánea boliviana bajo el mandato de Evo Morales, fortalecido tras el plebiscito de Agosto de 2008. Pienso que el enfoque específico que asumo en este artículo -sobre la nueva legislación educativa boliviana por una parte y la producción estética inspirada por el proyecto de la escuela indígena Warisata (1931-1938) por otra- puede echar, pars pro toto, nuevas luces sobre el proyecto general de Morales que anhela construir un nuevo Estado sobre la base de las prácticas culturales indígenas. ${ }^{1}$ Para lograr este

1 Urge analizar los paralelismos entre el discurso estético histórico de los integrantes vanguardistas vinculados con Warisata (entre ellos, me refiero sobre todo a Gamaliel Churata) y el discurso político contemporáneo, pues ambos coinciden en la idea de realizar un proyecto "descolonizador" -vocablo que se repite de manera excesiva en los textos oficiales del gobierno de Morales (el borrador de la Nueva Ley de Educación Boliviana incluido) a la vez que la crítica literaria boliviana lo está utilizando, con razón, para caracterizar la "vanguardia del Titikaka": "[...] esta vanguardia [...] fundó su lenguaje y su imaginario en un acto descolonizador que $[. .$.$] se resistía a entender la tragedia del indio a través de marcos ideo-$ lógicos provenientes de Europa [...] o derivados del templum del mestizaje o del 
objetivo, los políticos, al igual que artistas y escritores vinculados con Warisata, consideran, al parecer, que la educación es un elemento cabal para plasmar la utopía de un Estado "indoamericano" opuesto a las formas estatales desarrolladas desde Platón en el Occidente. Se produce así un caso singular en el que los modelos de la crítica literaria y los estudios culturales adquieren suma importancia -pienso sobre todo en Lotman (1982) y su idea de la literatura (y del arte en general) como un "sistema secundario" que permite la creación de mundos modélicos (aún) no reales con el fin de reflexionar sobre las consecuencias que arrastran en ellos ciertas acciones o estrategias y poder reajustarlas en caso de que resulten dañinas. Si bien la escuela de Warisata constituye una especie de núcleo ideológico (aunque tal vez inconsciente) de la actual política boliviana, hace falta reevaluar críticamente el discurso de Warisata -y no mitificarlo simplemente, a pesar de las simpatías que uno pueda tener por aquel proyecto pionero de los años 1930- para que la política de hoy no repita los errores de los intelectuales de entonces (emisores subalternos, por supuesto, pues nunca han sido escuchados de manera seria) que plasmaron su microEstado utópico en forma de una escuela rural basada en ciertas estructuras de las comunidades indígenas del altiplano, es decir en el ayllu. Para nosotros los críticos literarios, ello implica salirnos de la torre de marfil para rescatar y a la vez criticar el legado de la Escuela Ayllu de Warisata, resaltando las homologías discursivas que comparte con el discurso político actual. Aplicar las pautas metodológicas de la crítica literaria a un fenómeno cultural de los años 1930 y reproyectarlas luego al presente extra-literario puede abrir una vía alternativa para acceder a una concientización de las bases de una posible "nuova cultura" boliviana (permítanme recurrir aquí una vez más a un término de Gramsci 1991: 8) frente a los análisis de parte de sociólogos, historiadores, etnólogos, pedagogos, etc., que hasta ahora han trabajado sobre la Escuela Ayllu. ${ }^{2}$ En este sentido, el presente texto -que no es

indigenismo [...] los integrantes de esta vanguardia vieron en la afirmación de la razón andina, en sus mitos y rituales, un acto de emancipación de Europa pero también de las élites americanas republicanas" (Monasterios P. 2008: 1-2).

2 Warisata se tematiza, aunque en perspectivas bastante diferentes, en los trabajos de Sanginés Uriarte (1968), Kohler (1981), Salazar Mostajo (1986), Schroeder (1992), Howard-Malverde/Canessa (1995), Cordova de Hernichel (2000), Albó (2002), entre otros. Un enfoque parecido al mío asume Salazar de la Torre 
nada más que un primer esbozo de los posibles vínculos discursivos entre algunas obras artísticas de Warisata y el proyecto educativoestatal de Evo Morales- es, en primer lugar, una invitación para discutir desde el ángulo específico de una disciplina más allá de las ciencias sociales.

\section{La polémica acerca de la Nueva Ley de Educación Boliviana}

En 2006, el gobierno boliviano de Evo Morales presentó, a cargo del sociólogo y entonces Ministro de Educación Félix Patzi, el borrador de una nueva ley educativa. Después de haber provocado toda una serie de polémicas durante años, enunciadas tanto desde la derecha como de la izquierda, la ley por fin se ratificó en diciembre del 2010. ${ }^{3}$ Así, por ejemplo, el ex Arzobispo de La Paz, Mons. Luis Sáinz Hinojosa, declaró que la Iglesia católica ve en la nueva propuesta educativa "un gran peligro y un gran atropello para los profesores y para la educación en general", resaltando especialmente la educación sexual, la

(2006), pues reconstruye el discurso político de la Bolivia de entonces partiendo de la producción estética en Warisata.

3 El presente artículo cita el anteproyecto de la ley. No obstante, el análisis sigue válido, puesto que las modificaciones en la versión final y ratificada de la ley son relativamente pocas y no conciernen al ámbito ideológico que se expresa en ella. Nótese que las reacciones adversas no se distinguen, sorprendentemente, mucho de aquellas frente a la Ley de Reforma Educativa (LRE) bajo el gobierno neoliberal de Sánchez de Lozada en 1994, alabada entonces por ser la más avanzada del continente. En algunos sectores sociales persiste el rechazo a la educación bilingüe prevista ya por la LRE. Acerca de la LRE y sus antecedentes y las reacciones que provocó en la sociedad boliviana cf. Ströbele-Gregor (1996), Cordova de Hernichel (2000), Taylor (2004) y Drange (2007). El estudio más reciente llega incluso a comparar la LRE con la Nueva Ley de Educación Boliviana propuesta por el gobierno de Morales; con razón, Drange pregunta: "Was it necessary to abolish LRE?", señalando que la nueva ley tal vez no difiere tanto de la LRE por su contenido sino más bien por la forma en que debe ser implementada, implicando "a more drastic action" y "a more explicit emphasis on the indigenous peoples' own knowledge and wisdom, a knowledge that has never before been recognized as valuable to the governing classes". El ex Ministro de Educación, Félix Patzi, justifica la nueva ley frente a la LRE de la siguiente manera: “[...] la reforma educativa, dictada mediante Ley en 1994, tergiversó la demanda indígena y estableció la educación denominada intercultural y bilingüe. Este paradigma educativo no soluciona las fronteras étnicas, es decir la colonialidad de la estructuración social y la concepción del mundo de las sociedades indígenas y su idioma nativo, condenando a la propia población en una visión de 'ensimismamiento' como si fuese una minoría" (Patzi 2008). 
educación laica y la planeada creación de concejos comunitarios que "serán un peligro para el país, porque tendrán la facultad de inmiscuirse en la currícula de la educación". Así mismo, al otro lado del espectro político, se leen en la página web de $<$ marxismo.org $>$ fuertes ataques en contra de la nueva ley a la que se le reprocha partir "del supuesto falso de que en el campo impera predominantemente las formas de propiedad comunal de la tierra, de las formas de producción comunitaria". Además, se afirma que la nueva ley es etnocentrista y quiere "imponer una cultura comunitaria a los centros urbanos" y subordinar "la tecnología a la "cosmovisión milenaria de los pueblos originarios". Pero el reproche cabal de parte de los marxistas consiste en que la nueva ley

Es idealista porque reduce el problema de la colonización a un fenómeno puramente cultural y considera que la educación, por si misma, puede superarlo. Ignora que se trata de un fenómeno primero de dominación económica y que para acabar con él es preciso destruir la gran propiedad privada de los medios de producción para transformarla en social, acabar con la clase dominante nativa y expulsar al imperialismo del país. ${ }^{5}$

Al parecer se están replanteando, en pleno siglo XXI, las antiguas tesis indigenistas de Mariátegui sobre el problema de la tierra, opuestas al liberalismo de la burguesía avanzada con sus ideas de educar al indio para capacitarlo -sólo que en este caso esa posición liberal-burguesa se le habría de atribuir, paradójicamente, al gobierno indígena de Morales.

\section{Warisata y la Nueva Ley de Educación Boliviana}

Para indagar el conflicto que se refleja en la polémica anteriormente resumida, conviene volver a los años treinta del siglo XX, a Warisata, un pueblo ubicado en el altiplano boliviano, departamento de La Paz. Allí se fundó en 1931 el proyecto escolar indígena Warisata a través de la iniciativa de Elizardo Pérez y Avelino Siñani, a quienes Morales y Patzi les dedicaron su nueva ley que oficialmente se llama "Nueva Ley de Educación Boliviana 'Avelino Siñani-Elizardo Pérez".

$4<$ www.aciprensa.com/noticia.php? $\mathrm{n}=16645>(04.09 .2008)$.

$5<$ www.marxismo.org/?q=node/376> (04.09.2008). 
Fig. 1: Los fundadores de Warisata

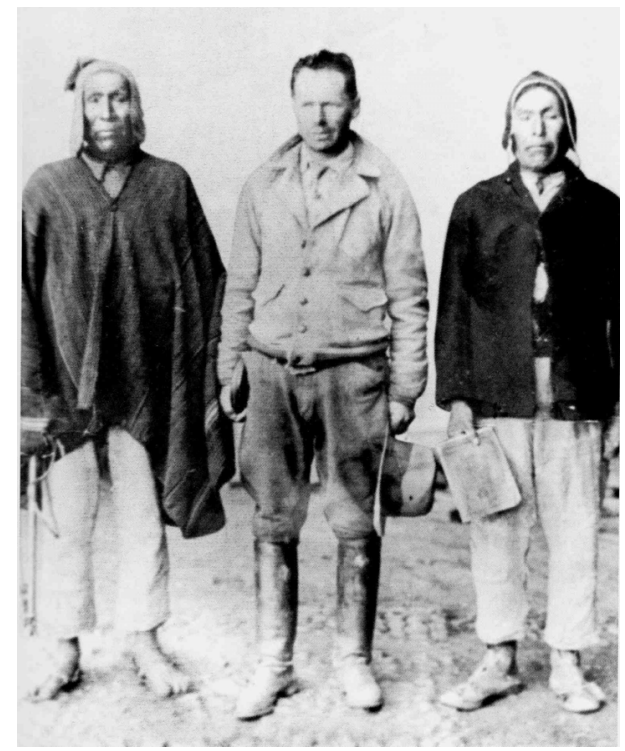

Elizardo Pérez (en el medio) y Avelino Siñani (derecha) Fuente: Salazar Mostajo (2005: 29).

Fig. 2: Patio del edificio principal de la escuela de Warisata con los murales de Illanes

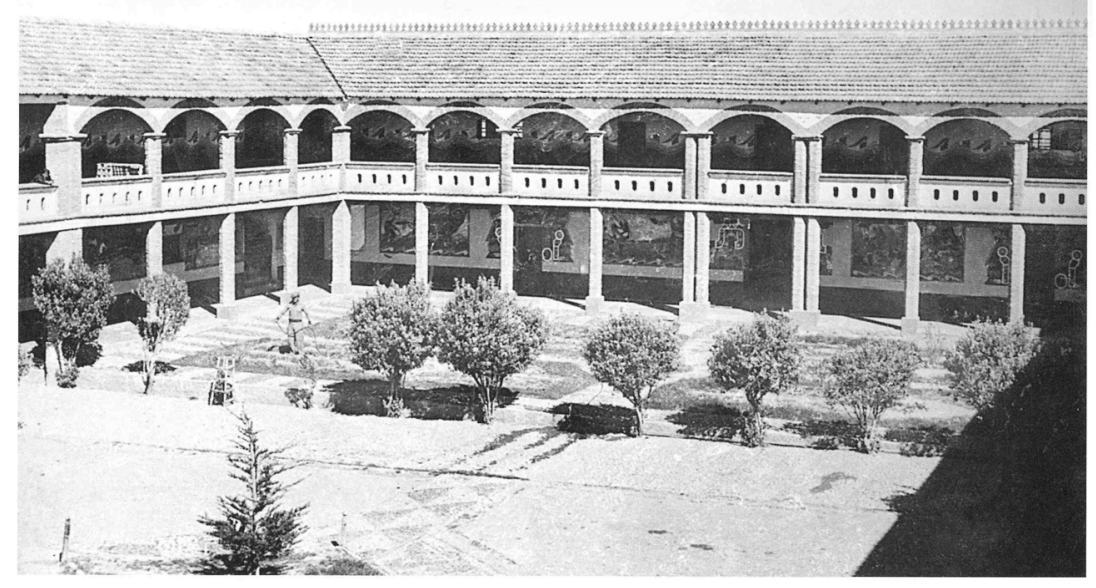

Fuente: Salazar Mostajo (2005: 101). 
A mi modo de ver, convivían en Warisata de manera intrínseca los dos tipos de indigenismos diferenciados por Lauer (1997): el indigenismo1 o sociopolítico y el indigenismo- 2 de alcance estético. ${ }^{6}$ Es muy característico el trabajo de concientización política de cuño abiertamente marxista entre los indígenas de Warisata (cf. fig. 3 en que podemos ver al trotskista Tristán Marof, junto con profesores de Warisata) tanto como el deseo de establecer un tipo de educación autodeterminada basada sobre un concepto de educación total que renuncie a toda reglamentación estricta por horarios y currículos practicados en otras escuelas de la época, incluyendo tanto las ciencias prácticas agropecuarias como la formación artística en talleres de artesanía, pintura, música, etc. ${ }^{7}$

Fig. 3: Tristán Marof (última fila a la izquierda) con profesores de Warisata

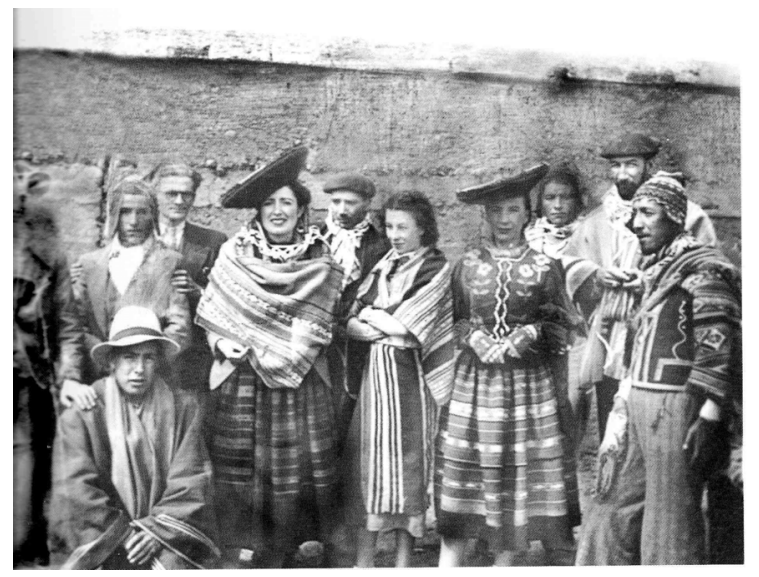

Fuente: Salazar Mostajo (2005: 81).

6 Asumo y mantengo la terminología a sabiendas de que esos indigenismos están perdiendo, con la participación política de los sectores indígenas, cada vez más sus matices indigenistas, adoptando un carácter indígena. No obstante, siguen presentes ciertos rasgos del discurso indigenista tanto en la política como en el arte de Warisata.

7 Para una sinopsis de la ideología de Warisata cf. Salazar Mostajo (1986). Téngase en cuenta, sin embargo, que su autor es uno de los profesores más destacados de Warisata (cuya obra artística inspirada por la experiencia en la escuela "ayllu" analizaremos en seguida), por lo cual a veces le resulta difícil asumir una posición objetiva y neutral. Cf. también los escritos del propio fundador, Elizardo Pérez (1962). 
Fig. 4: Pabellón México (detalle) con profesores de Warisata

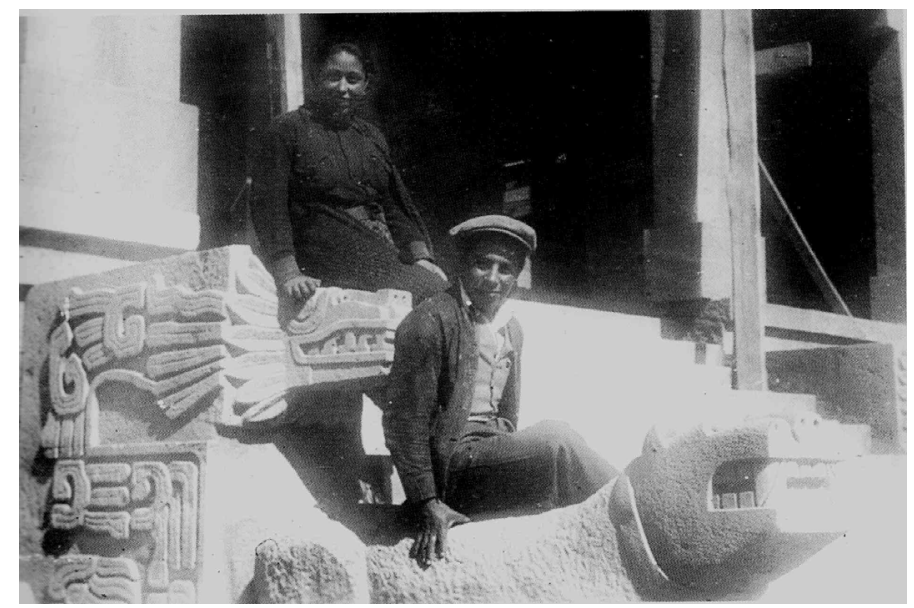

Fuente: Salazar Mostajo (2005: 81, 117).

La presencia permanente del arte en Warisata también se manifiesta en las fotos del así llamado Pabellón México (cf. fig. 4, 5 y 6), cofinanciado por el gobierno mexicano de Lázaro Cárdenas y construido, igual que el edificio principal (cf. fig. 2), por las propias manos de los indígenas de Warisata en un acto de trabajo colectivo llamado mincka o ayni (cf. Salazar Mostajo 2005: 93ss.). Aunque la construcción no se pudo terminar debido a que las autoridades bolivianas pusieron fin al experimento de Warisata en 1938, los lemas de los dos portales del pabellón (cf. fig 5 y 6 ) representan muy bien la reivindicación indigenista a la vez sociopolítica y estética-cultural que significó Warisata: "Trabajo es paz y libertad" por un lado y "Arte neoindio para el pueblo" por otro.

Semejante ímpetu reivindicador se refleja formalmente en la pedagogía de la "escuela única" de Warisata. Constituida por cuatro fases educativas distintas -el Jardín Infantil, la Sección Elemental, la Sección Vocacional y la Sección Profesional (Cordova de Hernichel 2000: 49-51)-, el currículo de Warisata siempre trató de integrar a los alumnos teniendo en cuenta su edad y capacidad física e intelectual, las cuales debían ser observadas y desarrolladas de manera individual por los profesores en el trabajo productivo comunitario y colectivo, a 
la vez que se les brindaba una educación en las asignaturas corrientes de la época, incluidas las artes. Este carácter colectivo parece hacer eco en la Nueva Ley de Educación Boliviana cuando ésta menciona a la Escuela Ayllu en el preámbulo ${ }^{8}$ y propone un nuevo currículo en el que se destaca el uso reiterado del adjetivo "comunitario".

\section{Fig. 5 y 6: Portales del Pabellón México con lemas}
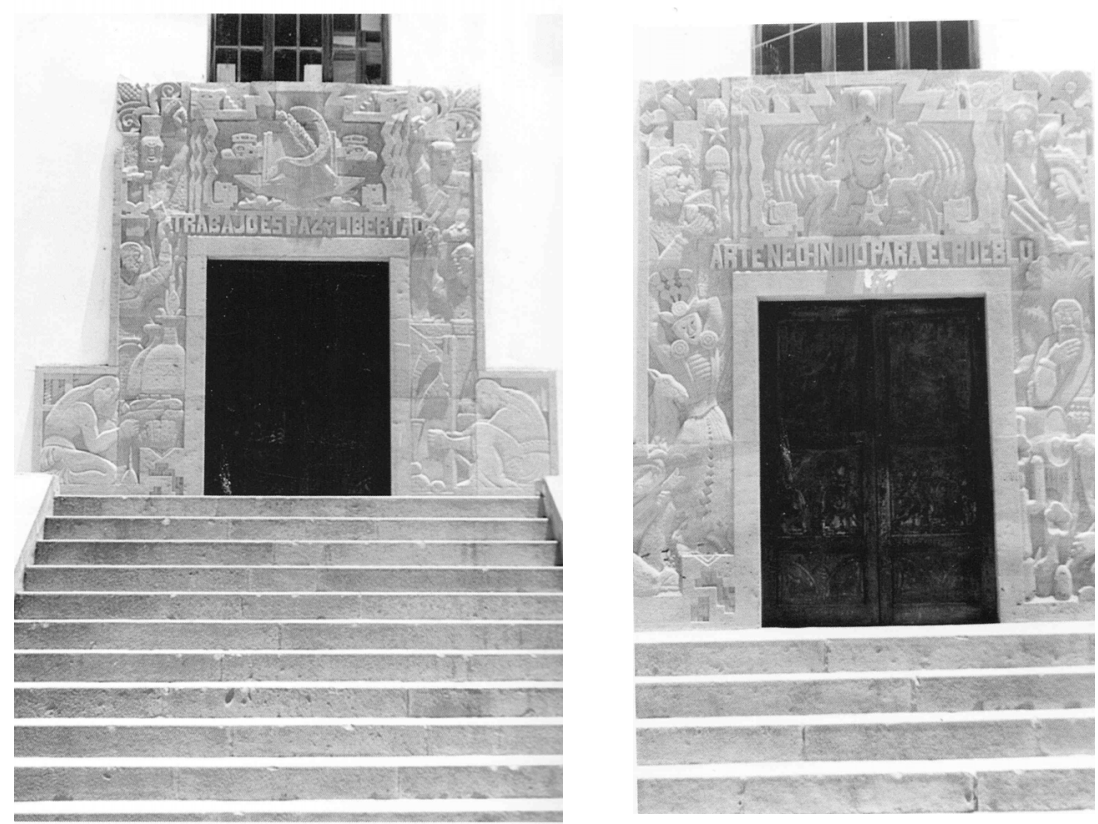

Fuente: Salazar Mostajo (2005: 256, 257).

8 Cf. Comisión Nacional de la Nueva Ley de Educación Boliviana (2006: 3): “[...] los maestros rurales de entonces impulsaron un movimiento reivindicador educativa que se plasmó en la experiencia pionera de Warisata, sustentada en la concepción y dinámica del ayllu indígena, que dió origen al sistema de educación rural que perdura hasta hoy, pese a que Warisata fue ahogada institucionalmente por la reacción feudal de aquella época."

9 Se trata de una educación comunitaria subdividida en una fase de "Educación en familia comunitaria", pre-escolar para niños de 0 a 5 años, seguida por la "Educación comunitaria vocacional" de una duración de 8 años, para luego por fin continuar con la "Educación comunitaria productiva" de 4 años de duración (cf. Comisión Nacional de la Nueva Ley de Educación Boliviana 2006: 15). 


\section{Warisata en la obra de Carlos Salazar Mostajo}

Los murales de Mario Alejandro Illanes en el patio del edificio principal de Warisata (cf. fig. 7 a 10) que ilustran muy bien este trabajo comunitario en los campos, parte íntegra del currículo de Warisata, ya han sido objeto de un reciente estudio perspicaz -razón por la cual renuncio aquí al análisis de la obra de Illanes. ${ }^{10}$ Sin embargo, hay otros murales que aunque geográficamente no estén ni hayan estado jamás en Warisata, ${ }^{11}$ mantienen lazos íntimos con la Escuela Ayllu. Tal es el caso del mural La creación de Warisata (cf. fig. 11) que nos da un panorama amplio del quehacer educativo en Warisata. Su autor es Carlos Salazar Mostajo, ex profesor en Warisata y luego, hasta su fallecimiento, profesor de Historia de Arte en la Universidad de San Andrés de La Paz.

\section{Fig. 7 a 10: Algunos de los murales de Mario Alejandro Illanes en el patio del edificio principal de Warisata que muestran el trabajo comunitario en la agricultura}

Fuente: Salazar Mostajo (2005: 266, 267).

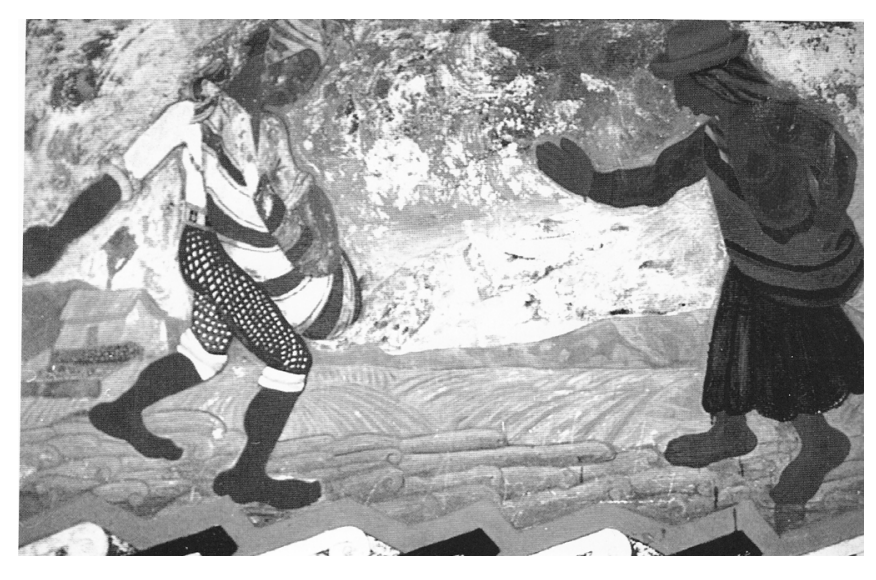

La siembra

10 Cf. Salazar de la Torre (2006) la que clasifica a Illanes de "expresionista" boliviano, epíteto tal vez cuestionable porque no veo ningún nexo directo con las escuelas expresionistas europeas; no obstante, el adjetivo transmite una idea concisa de la tradición estilística en que Illanes se inscribe, por más que la modifique $\mathrm{y}$ autoctonice. 

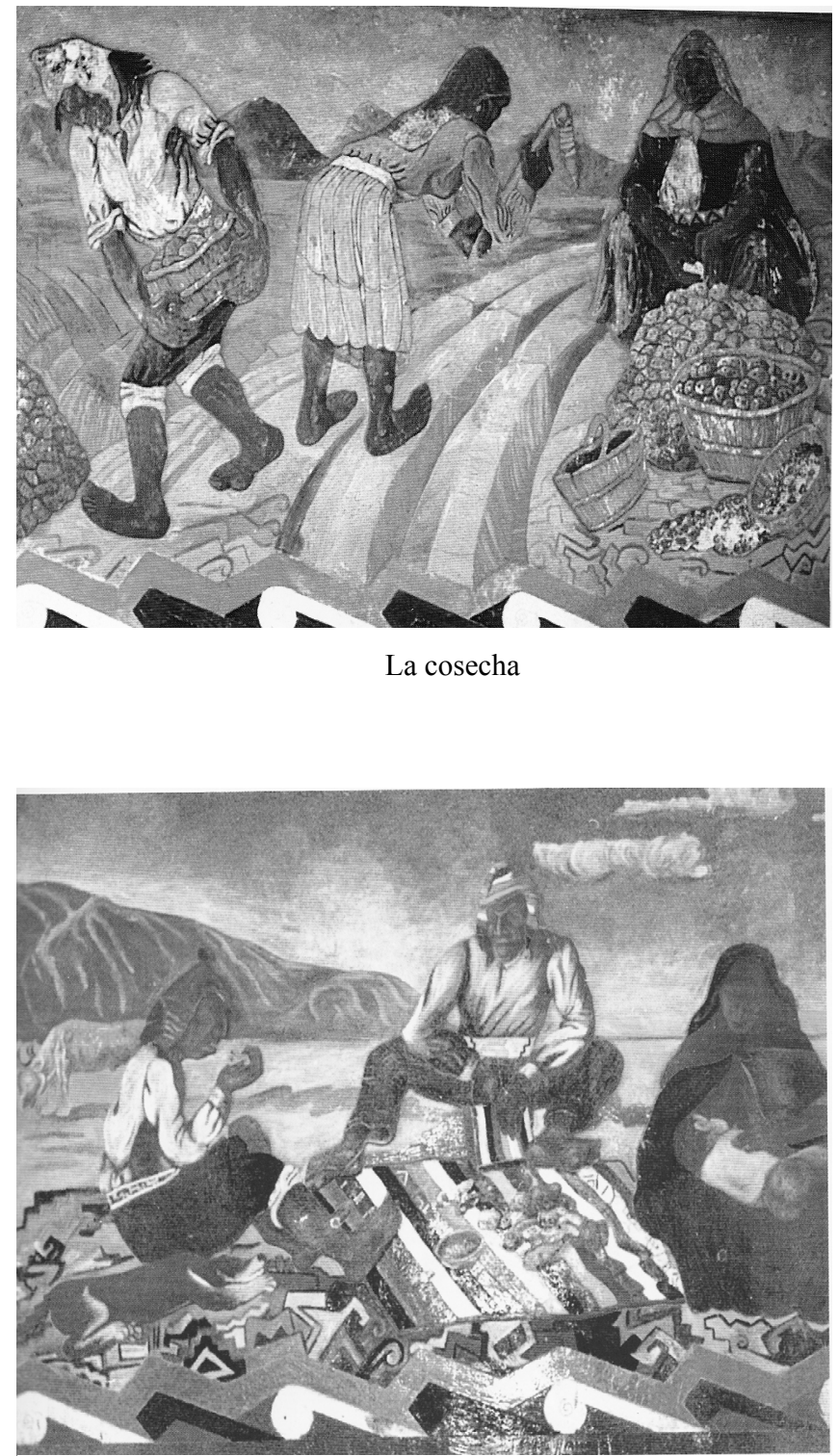

La merienda

11 Lo mismo cabría decir de los murales de Illanes, pues todos fueron destruidos. 


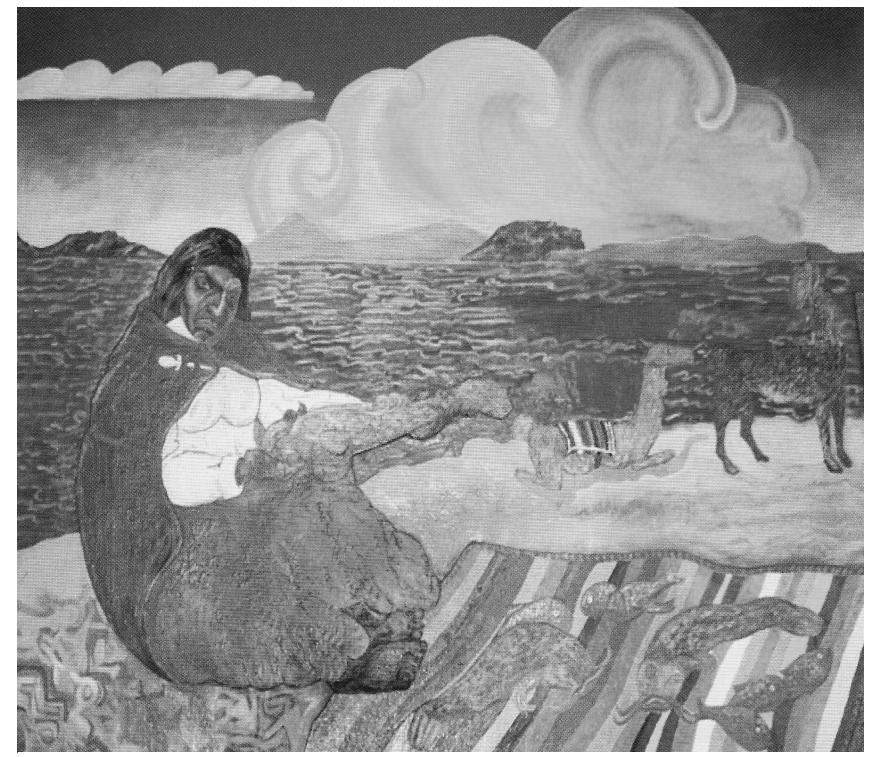

Vendedora de suches

En la parte izquierda superior del mural vemos a dos indígenas maltratados por un conquistador y un cura español y, según parece, también por un gamonal provinciano armado con un látigo y vistiendo un terno blanco. La parte derecha, en cambio, nos muestra una forma de opresión más sutil, menos violenta: la opresión por abogados, leguleyos y maestros convencionales que hacen uso del poder de la escritura para subordinar a los indígenas que de hecho no se encuentran a la misma altura que sus opresores. Delante de esta escena, como si le diera la espalda, vemos a Avelino Siñani, y luego, constituyendo el centro del cuadro, a Elizardo Pérez. Éste determina tanto el eje vertical con su cara o su nariz que subdivide el cuadro en la parte izquierda y derecha, como el eje horizontal con sus brazos y puños que señalan su convicción de lucha (cf. fig. 12). Este eje horizontal resulta luego duplicado por la fachada del edificio principal de Warisata, debajo de los brazos de Pérez que cual un Cristo Redentor parece proteger sus muros. Otra duplicación se produce con el mismo Elizardo Pérez (aunque parece que en realidad se trata del hermano de éste, Raúl Pérez, según me señaló la hija de Salazar Mostajo, Cecilia Salazar de la Torre) que aparece otra vez en la parte inferior del cuadro, ocupando nuevamente 
el centro del cuadro, pero enfatizando esta vez, con su brazo y puño levantados, el eje vertical en que se ubica por fin, en la primera fila, una estatua blanca, símbolo del arte que producen los indígenas de Warisata, pero también de su liberación a través del arte, ya que la estatua lleva todavía los restos de unas esposas rotas. ${ }^{12}$

Fig. 11 y 12: La creación de Warisata, de Carlos Salazar Mostajo
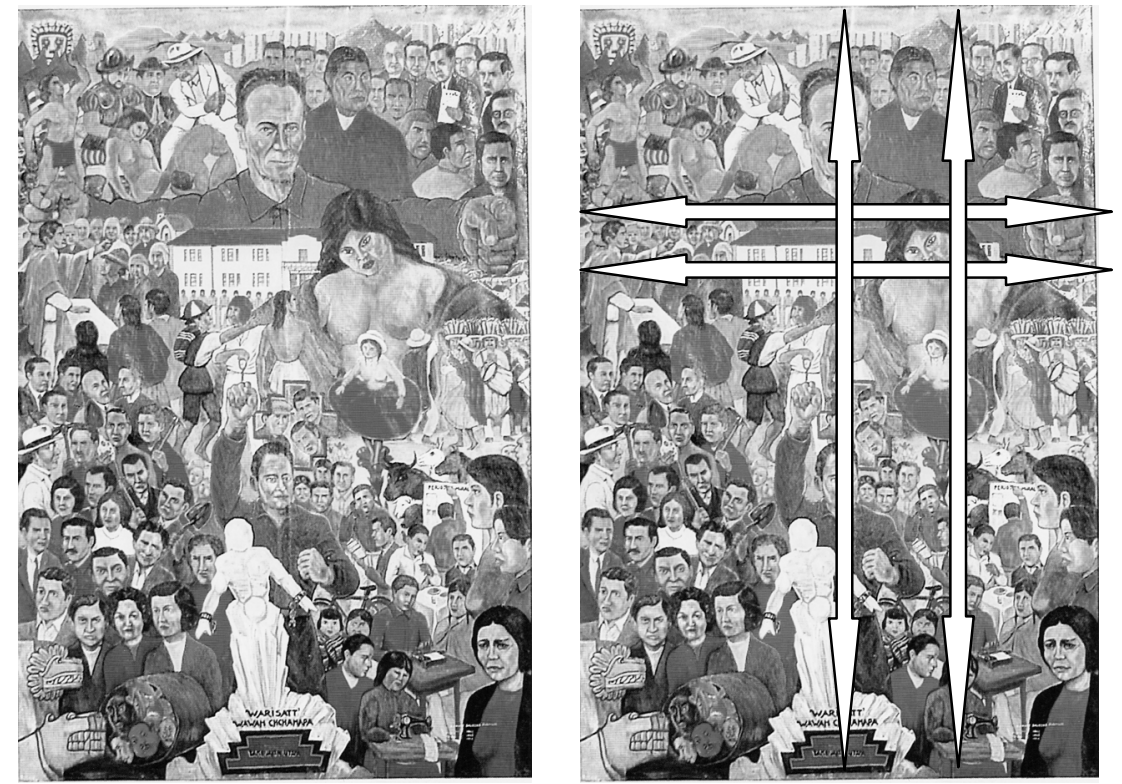

Fuente: Salazar Mostajo (2005: 269).

Sin embargo, hay que tener en cuenta también un segundo eje vertical subordinado al eje central (cf. fig. 12), constituido por Avelino Siñani y una mujer indígena con el torso desnudo de tamaño casi igual al de Pérez. Evidentemente, se trata de una alegoría de la Madre Tierra, de la Pachamama, vinculada además en el mismo eje vertical con su contraparte masculina de la cosmovisión andina ubicado encima de Siña-

12 En el pedestal de la estatua, se leen los lemas aymaras de Warisata: "Warisatt wawan chchamapa" ("El esfuerzo de los hijos de Warisata") y "Takke Jakken Utapa" ("La casa de todos"). Los mismos lemas también se podían leer encima del portal del edificio principal de la Escuela Ayllu. 
ni: un cerro, sede de los apus. Es bajo la tutela de la Pachamama, los muros de Warisata y los brazos de Pérez que se desarrolla, en la parte inferior derecha, una nueva vida indígena que reivindica tanto la tradición -la creencia en Pachamama, las danzas y la música antiguas, el trabajo agropecuario- como la modernidad, ya que los individuos retratados saben leer escribir y se integran en un régimen productivo moderno que les permite manejar máquinas de diversos tipos. En la parte inferior izquierda se hallan, por fin, empezando en la esquina extrema del cuadro, las representaciones de deidades mesoamericanas presentes en Warisata en forma del Pabellón México que hemos visto anteriormente (cf. fig. 4). Como la Pachamama personalizada, éstos también tienen su contraparte arriba en el divino sol andino ubicado en la esquina izquierda superior. Además, vemos en la parte izquierda a muchos mestizos y blancos, probablemente profesores de Warisata, que participan con sus palas en la construcción de la misma. Y finalmente, podemos observar encima de ellos, pero aún dentro del recinto protector que constituyen los muros de Warisata y los brazos de Pérez, a un grupo de indígenas que evocan, con sus chullos y vestimentos, a la ulaka, el gremio de los ancianos y sabios, o al Parlamento Amauta como también se solía designarla en Warisata.

En la foto al lado (cf. fig. 13) vemos a algunos miembros de la ulaka real de Warisata cuyos integrantes fueron quienes decidieron sobre los asuntos principales de la escuela -es la autodeterminación indígena tomada a pie de la letra. He aquí, al lado de la educación comunitaria y la ambición de capacitación plurilingüe que propone la Nueva Ley de Educación Boliviana, ${ }^{13}$ un tercer elemento cuyas reminiscencias al proyecto de Pérez y Siñani saltan a la vista -probablemente se trata del más controvertido: Me refiero a la creación de los así llamados "concejos educativos" previstos por el gobierno Morales que ejercerán, al fin y al cabo, la misma función que la ulaka de Warisata, logrando "inmiscuirse en el currículo de la educación", para re-

13 La ley prevé una educación trilingüe que comprende para todos los alumnos, además del castellano, una lengua indígena (en la mayoría de los casos el quechua o el aymara) y una tercera lengua extranjera. Sin embargo, parece que hay que relativizar el mito de la supuesta educación bilingüe de Warisata, pues también en la Escuela Ayllu predominaba el castellano (cf. Howard-Malverde/Canessa 1995). 
tomar las palabras del Mons. Hinojosa que los considera un "gran peligro". Estos concejos deben ser

[...] conformados por los actores básicos del proceso educativo que son: los estudiantes, los docentes y padres de familia representados por sus organizaciones legítimamente constituidas y las organizaciones comunitarias y populares de territorio existentes en el área de influencia del centro educativo [...] (Comisión Nacional de la Nueva Ley de Educación Boliviana 2006: 34).

Fig. 13: Miembros de la ulaka de Warisata

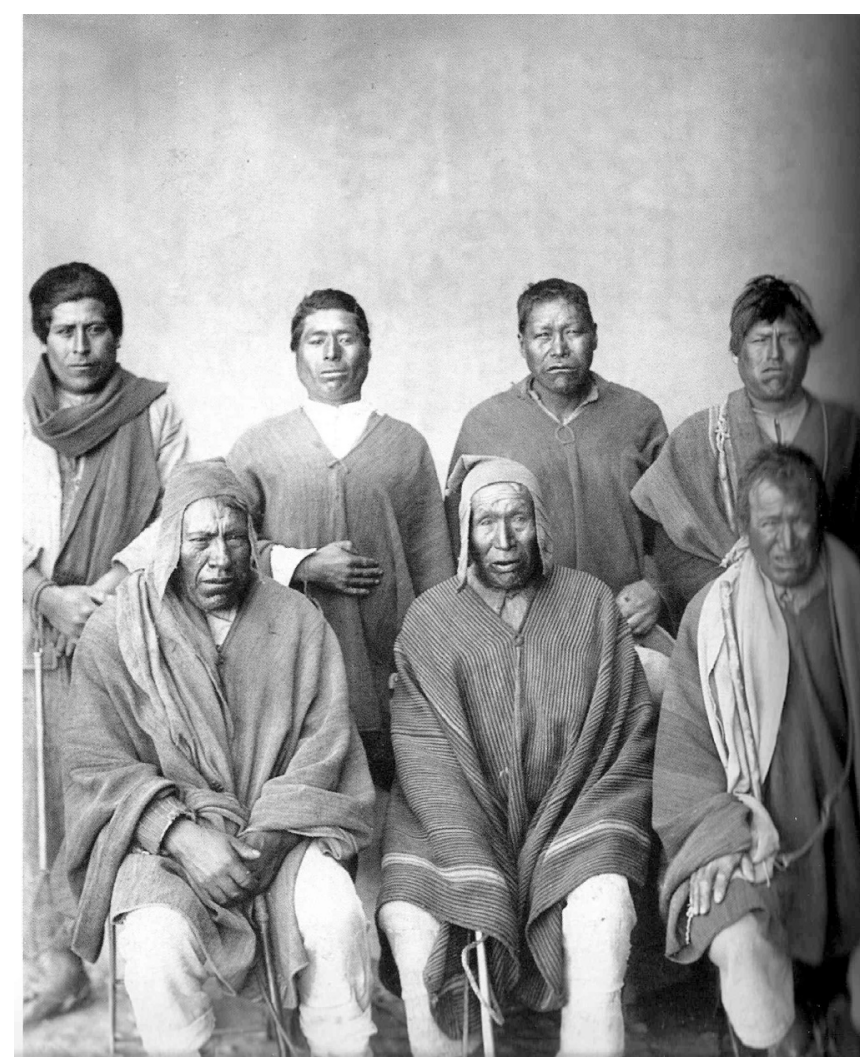

Fuente: Salazar Mostajo (2005: 30).

Según lo que plantea la ley, los concejos deben crearse en todos los niveles, desde la unidad escolar, a través del núcleo y de la región, 
hasta el supremo "Concejo Educativo Plurinacional" subordinado sólo al "Congreso Educativo Plurinacional" que será convocado cada cinco años.

\section{Warisata en la obra de Gamaliel Churata}

La ulaka de Warisata ha dejado sus huellas no solamente en la pintura y la nueva legislación educativa, sino también en la literatura. El periodista y novelista-ensayista Gamaliel Churata, peruano radicado en Bolivia desde 1932, parece haberse impresionado mucho por el impacto que el Parlamento Amauta de Warisata y la Escuela Ayllu en general ha ejercido sobre él, según consta una carta que Churata le escribió a su antiguo amigo y "ahijado" del grupo vanguardista puneño Orkopata, al poeta y dramaturgo quechua Inocencio Mamani:

Procura venir a visitarme. Haré lo posible para que vayas a Warisata y veas esa grandiosa obra que allí levantan los indios guiados por un hombre apostólico y sencillo, que es, sin embargo, uno de los hombres más importantes de Bolivia en este momento. Nosotros debemos percatarnos que la escuela que necesita el indio es esa $[\ldots] .^{14}$

Llama la atención el hecho de que Churata le asigna a Pérez, llamándolo un apóstol, el mismo papel cabal y central, casi mesiánico, que le corresponde también en el mural de Salazar Mostajo. Se deberá ello a la idea del padrinazgo andino, práctica que se manifiesta también en la actitud paternalista de la literatura indigenista de la época; la misma relación de padrinazgo existía también entre Churata y Mamani cuyas cartas contestatorias suelen empezar con las palabras "Querido padrino". En este sentido, el hecho de que la nueva ley mencione primero a Siñani y recién en segundo lugar a Pérez ha de interpretarse a la luz del proyecto "descolonizador" del gobierno de Morales que trata de eliminar los residuos paternalistas $\mathrm{y}$, por ende, clásicamente indigenistas del proyecto de Warisata para que la escuela pueda ser considerada, a posteriori, una creación verdaderamente indígena. ${ }^{15}$

14 Carta inédita de Gamaliel Churata a Inocencio Mamani, La Paz, 10 de mayo de 1934. Le agradezco a Riccardo Badini haberme facilitado el acceso a este documento.

15 No hay duda de que el rescate y la reivindicación de Siñani frente a Pérez son justificados y necesarios, pues según recuerda su hija Tomasa, fue "Elizardo Pérez, [el] que había venido a buscarlo" (Siñani de Willca 1992: 131-132) a Siñani cuando se fundó Warisata. Siñani ya se había dedicado a alfabetizar a los indíge- 
Fig. 14: Carlos Salazar Mostajo y Gamaliel Churata en Warisata

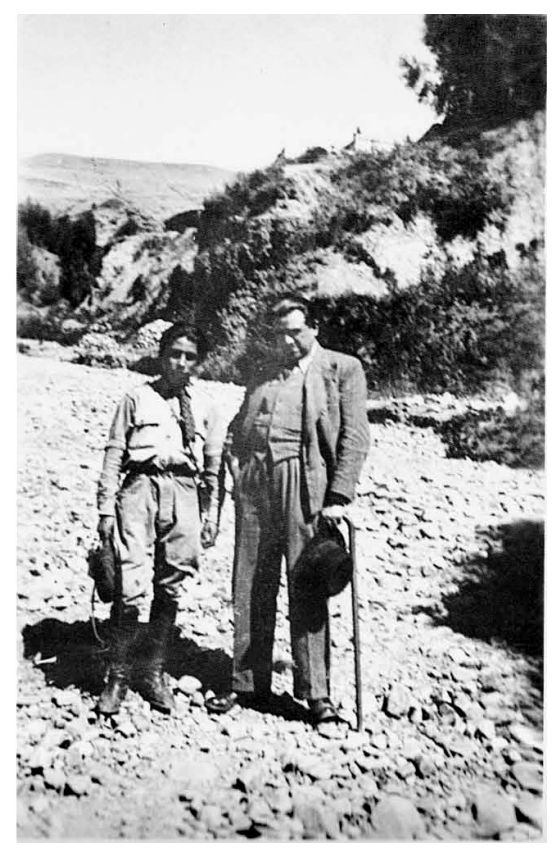

Fuente: Salazar Mostajo (2005: 80).

Acerca de Churata y de su novela-ensayo El pez de oro, publicada en La Paz en 1957, cabe decir algo parecido: El texto a veces se desplaza hacia un carácter indígena aunque nunca abandone por completo su postura indigenista. No en vano, el libro ha sido llamado por Omar Aramayo (1979) "la biblia del indigenismo" -expresión que reúne en sí tanto el aspecto apostólico como el paternalista-indigenista. Pero en el caso de Churata, se trata de un indigenismo escondido y muchas veces poco perceptible debido a su lenguaje altamente híbrido, lleno de neologismos y mezclas entre el castellano, el quechua y el aymara, que le otorgan a su obra una apariencia muchas veces más indígena que indigenista. Finalmente, el Pez de oro (o Khori-Challwa en que-

nas de la zona desde el primer decenio del siglo Xx. Durante un tiempo, los intereses de los políticos locales coincidieron con un proyecto de educación indígena pues en ese entonces a los analfabetos se les negaba el derecho al voto (cf. Siñani de Willca 1992: 128-129). Le agradezco a Esther Balboa haberme facilitado una copia del artículo de la hija de Siñani. 
chua) del título de la obra es un ser apostólico, pues encarna como hijo de una sirena y un puma (es decir entre un animal anfibio y un felino que señalan en la iconografía andina el pachakuti) el comienzo de una nueva era (Bosshard 2002: 94; 2007: 522).

El largo capítulo "Morir de América", con el cual el libro termina y el que aquí nos ocupa, constituye una especie de Politheia andina. Con y contra Platón, ${ }^{16}$ Churata plasma allí las estructuras de un Estado indoamericano $-\mathrm{y}$ es por eso que urge la relectura atenta de este texto con vistas a las ambiciones del gobierno de Morales. El capítulo contiene una escena en la que el padre del Pez de oro, el soberano Puma de oro (Khori-Puma), se dirige a la ulaka. El hecho de que en su discurso delante de ella se refiera a la Guerra del Chaco (1932-1935) entre Bolivia y Paraguay, asumiendo la perspectiva boliviana (a pesar de que el autor real Churata es peruano), demuestra que esta parte del libro debe haber sido escrito en Bolivia durante los años treinta, haciéndole eco al Parlamento Amauta de Warisata. ${ }^{17}$ El Khori-Puma trata de convencer la ulaka para que acepte las reformas que sugiere. Enfatiza, por un lado, los méritos del Parlamento de haber conservado las estructuras sociales comunitarias:

-Alabo con veneración, respetables Hiliris- en señalada asamblea de la Ulaka sostuviera tu Khori-Puma-; alabo la organización que habeis [sic!] conservado de nuestros antepasados, cuya sabiduría nos obliga a desearles diario nido en nuestro corazón, y que en él, enternecidos, se acurruquen, como en su thapita el Cherekheña de Orko-pata (Churata 1957: 459).

Pero por otro lado, no deja lugar a dudas que conservar sin cambiar o modernizar resulta imposible:

Así observad que el cambiar es índole de lo permanente; si para cambiar será forzoso parar, y sólo para lo que tiene naturaleza de estancia. Lo inestable podrá cambiar, si cuando lo quiera tendrá ya dónde querer. [...] Ved en esto que la estructura del poder gobernante entre nosotros es in-

16 Churata siempre recurre a la pregunta retórica “¿Entiendes, Plato?” cuando presenta una propuesta alternativa.

17 Cf. Churata (1957: 462-463) en que la alusión a la Guerra del Chaco resulta bastante obvia: "Suponed que nos hallamos en guerra. [...] La Ulaka debe decidirlo. Nuestro país tiene en los actuales momentos otra amenaza [...] Acaso debamos atribuirnos el ingrato papel de agresores. [...] en un Estado como el nuestro, [...] una democracia, el Khori-Puma no puede sacrificar la vida de ninguno de sus conciudadanos sin que lo haya previamente considerado el Consejo [...]". 
completa y está, por poco menos, al margen de las leyes de la vida (Churata 1957: 459).

Sin embargo, estas y otras reformas (que incluyen también el derecho de la mujer a participar en el nuevo Estado indígena que se plasma), ${ }^{18}$ no son aprobadas por la ulaka, entre ellas también el proyecto del Khori-Puma que consiste en romper con la tradición de que "el mandato del Emperador debía ser irrenunciable, si su origen dinasta así lo determinaba" (Churata 1957: 454) -es decir, al menos por decisión propia el (buen) soberano puede/debe evitar que se produzca un mandato indefinido, aunque para la ulaka éste sea normal y aceptable. ${ }^{19}$ Las reformas recién se realizarán a través del "Príncipe revolucionario", es decir del Khori-Challwa, hijo del Khori-Puma y futuro Emperador. Es aquí donde surge un problema cabal: Aunque el Estado plasmado por Churata es, en el fondo, un Estado democrático, siguen presentes elementos arcáicos, autoritarios y casi monárquicos opuestos a la idea de la democracia occidental. ${ }^{20}$ A pesar de que el (buen) soberano, el Khori-Puma, rechace la monarquía por herencia y opte por un sistema democrático, ${ }^{21}$ la ulaka elige como sucesor a su hijo, el apostólico Khori-Puma, porque juzga que "entre los ciudadanos hábiles,

18 Sin embargo, Churata no llega a concederle a la mujer una posición equivalente a la del varón sino que la sigue considerando como mero complemento dependiente del hombre, centrada en la reproducción biológica. No concibe a la mujer "en cuanto individuo profesionalmente apto" sino "como varona, parte del varón, como madre, productora de vida" (Churata 1957: 460). Con respecto a estas tensiones, irresueltas en Churata y los Orkopatas, entre discursos reivindicadores raciales y genéricas/sexuales cf. Bosshard (2006).

19 Dadas estas reflexiones en torno al tema democracia vs. autoritarismo en el seno del "sistema secundario" que es la literatura, haría falta urgentemente problematizar del mismo modo declaraciones bastante ambiguas enunciadas en el "modelo primario", es decir, en la realidad de la política boliviana que se refieren al mandato de Morales: "Evo Morales no es sólo un líder de los bolivianos sino de toda América latina y el mundo. No va a ser presidente por una gestión, lo queremos, y así lo han planteado los compañeros, por 50 años y quizás mucho más." (Gerardo García, vicepresidente del MAS, cf. <www.bolpress.com/ art.php?Cod=2007040307>; 04.09.2008)

20 No se olvide, sin embargo, que la visión de Platón tampoco tiene mucho que ver con el concepto contemporáneo de la democracia.

21 Cf. Churata (1957: 454-455): "Mi proyecto establecía, que el Rey del Titikaka debía elegirse entre los ciudadanos virtuosos, conforme a vieja tradición que contraría la doctrina de que el Llautu se obtenía por herencia [...] Otorgar [...] el Llautu al hijo, por ser hijo del Gobernante, la tradición secular lo autoriza, y aunque puede justificarse en muchos casos, no es lo más saludable.” 
con mayores títulos que El [Pez de oro, no había], ninguno" (Churata 1957: 456). Así, se le atribuye al Pez de oro aquel carácter apostólicomesiánico que coincide con el del ideal de un "Poeta-Ministro" que esté en armonía no solamente con la ulaka, sino también con la naturaleza sobre cuyas leyes debe establecerse el Estado (indígena):

El Estado asuma la orgánica de la Naturaleza, que si ha creado vísceras es para que concurran a las funciones vitales, y sean de su función [...] Así, pues, no quiero ministro de Educación poeta; os encarezco darme un Poeta-Ministro, que actúe en el seno de la Ulaka desde el campo de acción de la poesía (Churata 1957: 465).

$\mathrm{Y}$ de hecho, una de las primeras acciones del Pez de oro consiste en presentarle a la ulaka unas leyes educativas que conciernen la formación de maestros para que sean ratificadas. ${ }^{22}$ Dice el primer artículo:

\section{LEYES DE EL PEZ DE ORO}

$1^{\circ}$. - Sólo se admitirá en las Facultades Pedagógicas, a quienes, sometiéndose a minuciosas y prolongadas observaciones en orden a su vocación, demuestren ingénita aptitud de maestros (Churata 1957: 484).

Esa "ingénita aptitud de maestros" que se requiere en $E l$ pez de oro para poder fundar aquel nuevo "Imperio [que] es sólo ese ayllu" (Churata 1957: 475), es decir que "parte de la célula" (Churata 1957: 475) comunitaria andina vinculada orgánica y espiritualmente con la naturaleza, parece precisarse unos cincuenta años más tarde en la Nueva Ley de Educación Boliviana:

Artículo $4^{\circ}$ (Objetivos) Formar maestros en educación con:

1. Vocación de servicio a la comunidad, con calidad y pertinencia pedagógica y científica, identidad cultural y de clase, actitud crítica, reflexiva y contextualizada a la realidad sociocultural. [...]

22 Al escribir estos párrafos, Churata habrá pensado, además de recordar sus experiencias en Warisata, también en José Antonio Encinas, profesor de Churata en la Escuela Fiscal $N^{\circ} 881$ de Puno, años antes de que Encinas se convirtiera en uno de los pedagogos más importantes de la época, llegando a ser rector de la Universidad Nacional Mayor de San Marcos de Lima, la más antigua universidad del continente. Más tarde, Churata le escribió el prólogo al libro de Encinas Un ensayo de escuela nueva en el Perú (1930). En 1939, Encinas visitó, muy probablemente gracias a Churata, la Escuela Ayllu de Warisata y se quedó un mes entero enseñándoles a los profesores (cf. Salazar Mostajo 2005: 79). 
3. Capacidad de recuperar, recrear, desarrollar y difundir la tecnología, ciencia, arte, valores, espiritualidad, conocimientos y saberes de las naciones indígenas originarias, afroboliviano y otras culturas en el marco del proceso de descolonización.

$[\ldots]$

(Comisión Nacional de la Nueva Ley de Educación Boliviana 2006: 2223).

Ahora bien, ¿qué significa todo eso? ¿Acaso podemos identificar, con base en estas alusiones intertextuales, al ex Ministro de Educación Patzi con aquel Poeta-ministro "que actúe en el seno de la Ulaka"? ¿O coincide más bien con el apóstol de una nueva era, es decir con el Pez de oro de Churata, mientras que al presidente Morales le corresponde el Khori-Puma? No nos desconcierte el hecho de que Patzi fuera destituido de su función por Morales a fines del 2006, es decir poco después de la primeras polémicas alrededor de la nueva ley educativa, pues forma parte del ideario de Churata en que el hijo renace en el padre, de modo que el mítico Khori-Puma puede devorar a su propio hijo sin que éste se muera definitivamente. ${ }^{23}$ En este sentido, aunque Patzi no ha vuelto a ser ministro, el nuevo Ministro de Educación, bajo cuya administración la ley por fin se ratificó -Roberto Aguilar-, constituye una especie de re-encarnación de Patzi, puesto que los elementos cabales del borrador de la antigua "Ley Patzi" se han mantenido. Es muy llamativo, de todas maneras, que el Khori-Puma sea caracterizado por Churata siendo un ser originario, puro, procedente de una época lejana donde aún regía el matriarcado, el culto vulvar. ${ }^{24} \mathrm{Se}$ trata de un indígena que prepara lo que realizará más tarde el híbrido Khori-Challwa, pez volador, sirena y puma en un solo personaje: una "Revolución [que] no es revolusionar. Al contrario, es redescubrimiento de la célula; es religar: religión: unir al individuo con su espacio" (Churata 1957: 472). Así, el Pez de oro, mestizo neoindio (según Uriel García), deviene el emblema ideal de aquel "Estado plurinacional" y sus estructuras educativas que esboza el nuevo gobierno boliviano. En el $1^{\circ}$ artículo, párrafo 6 , leemos que la nueva educación boliviana

23 Cf. Churata (1957: 130): "Pudo el Puma con el hambre de su diente, y enloquecido por el Oro, se comió a su hijo [...]." Poco después, el Pez de oro resuscita en el charco formado por las lágrimas de su padre, el Puma de oro (cf. Churata 1957: 131).

24 Cf. Churata (1971: 14): "el Khori-Puma, el Puma de Oro, [es el] símbolo del hombre matriarcal, de la edad lunar". 
Es universal, única y diversa. Universal porque atiende a todos los habitantes del Estado Plurinacional. Única en cuanto a calidad y contenido curricular básico. Diversa en su aplicación y pertinencia a cada contexto geográfico, social, cultural y lingüístico (Comisión Nacional de la Nueva Ley de Educación Boliviana 2006: 4).

La yuxtaposición irresuelta entre lo "universal" y lo "diverso" que se manifiesta en esta cita, típica para la heterogeneidad andina del tipo tinkuy, equivale a la misma ambigüedad presente hasta las últimas páginas del libro de Churata. Allí tenemos, por un lado, el nexo de la célula particular con el Cosmos universal cuando leemos: "Es que lo indio es lo que caracteriza la célula, como la célula caracterológica del Cosmos. O séase que sólo tiene cosmos quien tiene célula" (Churata 1957: 532-533). Por otra parte, se enfatiza la particularidad: la pertenencia étnica, racial y psicológica, en pasajes como: "Parece que el mestizaje ni morbo alguno alcanzan a la célula genésica. Somos indios, o no somos de América" (Churata 1957: 532). O: "Cualquier mestizaje es imposible, mas hay alguno impasable; y uno [...] es el del hispano y las lenguas aborígenes de la América" (Churata 1957: 533). Dadas esas tensiones entre lo universal y lo particular, pero también entre lo mestizo y lo indígena que se experimentan hasta hoy en la realidad cotidiana de Bolivia, Churata se escapa al ámbito del lenguaje: Según él, es allí -y sólo allí- donde el mestizaje puede efectuarse con éxito. Esa conclusión de Churata puede parecer a primera vista bastante pesimista. Pero literalmente, ello significaría que las capacidades inter y transculturales pueden ser adquiridas y desarrolladas a través del lenguaje -esto es, también a través del estudio de obras como la de Churata en las que predomina un lenguaje híbrido, mestizo y polivalente. No hace falta remitir a Heidegger y a su idea de que el lenguaje es la casa del ser para poder darse cuenta de que la comprensión de aquél difícil lenguaje pluricultural facilitaría a la vez la estimación del lugar, pluricultural también, en donde viven los bolivianos.

\section{A manera de conclusión}

He intentado en este artículo esbozar, partiendo desde el arte y la literatura, el discurso de Warisata y sus repercusiones en la sociedad contemporánea. Las observaciones hechas en el campo del indigenismo-2, o sea dentro del "sistema secundario" que constituye el arte, necesariamente se deben actualizar a la luz del indigenismo-1 al trasladarlas 
al ámbito sociopolítico de la realidad boliviana. Me parece que el elemento más ambiguo y, por ende, más peligroso del discurso estético de Warisata es el mesianismo, esa creencia ciega en una figura apostólica salvadora e irracionalmente enaltecida que no sólo es el emblema de un pachakuti sino que provoque activamente el comienzo de una nueva era, mientras que los demás siguen en una posición mucho más pasiva. Hemos podido observar variantes de este mesianismo tanto en la estructura jerárquica y céntrica enfocada en la imagen de Elizardo Pérez (que con sus brazos abiertos en forma de una cruz remite a la iconología del Cristo Redentor) en el mural de Salazar Mostajo como en las cartas y la obra de Gamaliel Churata donde este fenómeno asume la forma de las encarnaciones apostólicas del Puma y del Pez de oro. ${ }^{25}$ Modificar la jerarquía, es decir, sustituir simplemente a Elizardo Pérez por Avelino Siñani, tal como lo hace la Nueva Ley de Educación Boliviana cuando invierte el orden de los dos fundadores de Warisata al nombrarlos, no elimina en absoluto el mesianismo inherente a este tipo de discurso, sino que solamente lo viste con un disfraz indígena. A mi modo de ver, siguiendo un procedimiento deconstructivista ya clásico, se trataría más bien de invadir, usurpar y abolir el centro desde los márgenes -y figuradamente hablando, si me refiero al mural de Salazar Mostajo, los sujetos que están ubicados en estos márgenes y a los que les corresponde realizar esta tarea es mayormente a los subalternos, los indígenas de Bolivia en general: Son ellos los que tienen que actuar y no sus dirigentes apostólicos. Pero desde luego, para poder actuar y participar democráticamente se requiere una previa conscientización $-\mathrm{y}$ es aquí donde entra en juego la educación, la cual constituye efectivamente la matriz o "célula vital" (Churata) de cualquier sociedad o Estado "nuevo".

Con respecto a la política actual, me parece que hay que rechazar rotundamente -por más solidaridad que uno sienta hacia el proyecto de Morales- la idea de una prolongación (casi) indefinida del mandato presidencial que tanto parece gustarles a algunos funcionarios desta-

25 Sigue presente semejante mesianismo también en textos contemporáneos. Por ejemplo, se lee en la portada de un trabajo-balance reivindicativo, pero bastante informal sobre la Escuela Ayllu acerca del libro Warisata. La Escuela-Ayllu de Pérez (1962): "De todos los libros que he leído sólo hay uno que vale la pena leer y si hay alguna Biblia que predicar es Warisata Escuela-Ayllu" (Mejía Vera s/a: 1). Se trata de un comentario de la propia autora del informe. 
cados del MAS (cf. nota 19), porque es allí donde se perpetuaría e institucionalizaría el mesianismo. Como bien demostró Alberto Flores Galindo (1986), todas las rebeliones andinas basadas en utopías mesiánicas al fin y al cabo fracasaron -por eso, no hay motivo para repetir el mismo error. Pero es importante agregar que de los fracasos se halla una lección; sírvannos de ejemplo no solamente las rebeliones campesinas del pasado, sino también el caso de las vanguardias históricas en las artes, de las cuales Illanes, Salazar Mostajo y Churata formaban parte. Pero al contrario de los movimientos vanguardistas europeos cuyo fracaso se debe, según la fórmula de Bürger (1974), a que no lograron reunir el arte con la vida, pienso que este no fue necesariamente el problema de los movimientos americanos, pues justamente en las utopías de Churata, Illanes, Salazar Mostajo, etc., el arte no se alejó nunca de la vida, sino que mantuvo gracias a la subyacente cosmovisión indígena, sus lazos con la naturaleza orgánica que genera la vida. Las razones de su fracaso más bien tienen que ver con que estos artistas carecían de un "público" suficientemente grande que hubiera podido defender y multiplicar sus ideas. La recepción de sus obras era, debido a la ignorancia intercultural de las capas hegemónicas blancas de entonces, casi nula. En la Bolivia de hoy, en cambio, sí existen recipientes "neoindios" potencialmente capaces de comprender -ipero también de criticar!- las propuestas de Churata y de los demás artistas vinculados con Warisata. Quienes aún no han empezado a leer El pez de oro, deberían hacerlo ahora. Pero también tienen que leerlo aquellos sectores sociales -blancos en su mayoría- ajenos e incluso hostiles a los códigos culturales indígenas que promueve la novela y, asimismo, a la Nueva Ley de Educación Boliviana - pues he aquí el antiguo espejismo entre la sociedad y el arte: Si los alumnos bolivianos no llegan a tener una idea crítica de la visión estética de obras artísticas como las de Churata, Illanes o Salazar Mostajo, tampoco habrá -no por causalidad, pero por analogía- una nueva educación ni un nuevo Warisata, y menos un nuevo Estado. Es aquí donde la educación estética no solamente es cabal para los indígenas, como en Warisata, sino también para los sectores no indígenas. Lo anterior puede servir para que éstos se familiaricen a través de un nuevo canon transmitido por el currículo escolar con los códigos culturales de un "Estado plurinacional". Aunque puede que para muchos estos códigos resulten a primera vista tan incomprensibles como resultaron entonces 
los códigos de la vanguardia estética, el hecho de que hoy en día es posible aclarar didácticamente el alcance y la importancia de un poema o texto vanguardista (como el de Churata), por más "raro" que sea, implica que debería ser posible realizar también una lectura comprensiva del texto de cualquier nueva constitución que, por fin, incluya todo lo -supuestamente- "raro", "ajeno" y "extraño" que constituye una nación multicultural como la boliviana.

\section{Bibliografía}

Albó, Xavier (2002): Iguales aunque diferentes [Cuaderno de Investigación, 52]. La Paz: CIPCA.

Aramayo, Omar (1979): El pez de oro, la biblia del indigenismo. Puno: Mimeo.

Bosshard, Marco Thomas (2002): Ästhetik der andinen Avantgarde. Gamaliel Churata zwischen Indigenismus und Surrealismus. Berlin: Wissenschaftlicher Verlag Berlin (wvb).

- (2006): "Virilidad y vanguardia: Construcciones de identidades masculinas y representaciones de lo femenino en Abril, Adán, Hidalgo, Varallanos y Churata". En: García-Bedoya M., Carlos (ed.): Memorias de JALLA 2004 Lima. Jornadas Andinas de Literatura Latinoamericana, vol. I. Lima: Universidad Nacional Mayor de San Marcos, pp. 171-186.

- (2007): "Mito y mónada: la cosmovisión andina como base de la estética vanguardista de Gamaliel Churata". En: Revista iberoamericana, LXXIII, 220, pp. 515-540.

Bürger, Peter (1974): Theorie der Avantgarde. Frankfurt am Main: Suhrkamp.

Churata, Gamaliel (1957): El pez de oro. Retablos del Laykhakuy. La Paz: La Canata.

- (1971): Antología y valoración. Lima: Instituto Puneño de Cultura.

Comisión Nacional de la Nueva Ley de Educación Boliviana (2006): Proyecto de Ley. Nueva Ley de Educación Boliviana “Avelino Siñani-Elizardo Pérez”. La Paz (<www.minedu.gov.bo/minedu/nley/nuevaley14sept.pdf>; 04.09.2008).

Cordova de Hernichel, Vilma Silvana (2000): Das Erziehungs- und Bildungssystem in Bolivien und das Projekt zu dessen Reform unter besonderer Berücksichtigung der Lehrerbildung für den städtischen und ländlichen Raum. Frankfurt am Main: Verlag Neue Wissenschaft.

Drange, Live Danbolt (2007): "Power in Intercultural Education: Education in Bolivia - from Opression to Liberation?". En: Journal of Intercultural Communication, 15 (<www.immi.se/intercultural/nr15/drange.htm>; 04.09.2008).

Flores Galindo, Alberto (1986): Buscando un inca. Identidad y utopía en los Andes. La Habana: Casa de las Américas.

Gramsci, Antonio (1991): Letteratura e vita nazionale. (Quaderni del carcere). Roma: Editori Riuniti. 
Howard-Malverde, Rosaleen/Canessa, Andrew (1995): “The School in the Quechua and Aymara Communities of Highland Bolivia". En: International Journal of Educational Development, 15, 3, pp. 231-243.

Kohler, Liu (1981): Unterdrückt, aber nicht besiegt. Die bolivianische Bauernbewegung von den Anfängen bis 1982. Bonn: ILA.

Lauer, Mirko (1997): Andes imaginarios. Discursos del indigenismo-2. Lima: Sur Casa de Estudios del Socialismo.

Lotman, Yuri M. (1982): Estructura del texto artístico. Madrid: Fundamentos.

Mejía Vera, Yvette (s/a): Warisata. El modelo de ayllu: Sistematización de Warisata Escuela-Ayllu 1931-1940. En: <www.katari.org/warisata/escuela.pdf> (04.09. 2008).

Monasterios P., Elizabeth (2008): "La vanguardia plebeya del Titikaka: Conciencia crítica y anti-hegemónica de un debate descolonizador". Manuscrito de la conferencia dada en las VIII Jornadas Andinas de Literatura Latinoamericana (JALLA). Santiago de Chile, 14 de agosto de 2008.

Patzi, Félix (2008): "Warisata enseñó que se puede 'aprender haciendo'. El primero de los paradigmas educativos en el país". En: La Razón, 16 de julio de 2008 (<www.la-razon.com/versiones/20080716_006335/nota_244_633088.htm>; 04.09.2008).

Pérez, Elizardo (1962): Warisata. La Escuela-Ayllu. La Paz: Ed. Juventud.

Salazar de la Torre, Cecilia (2006): "Estética y política en la Escuela-Ayllu de Warisata. Una aproximación al expresionismo de Mario Alejandro Illanes". En: Allpanchis, 68, pp. 175-195.

Salazar Mostajo, Carlos (1986): La Taika. Teoría y práctica de la Escuela Ayllu. La Paz: Ed. Juventud.

- (2005): Gesta y fotografía. Historia de Warisata en imágenes. La Paz: Lazarsa.

Sanginés Uriarte, Marcelo (1968): Educación rural y desarrollo en Bolivia. La Paz: Don Bosco.

Schroeder, Joachim (1992): Schule der Befreiung? Die Kernschule als Lehrstück für Schulreformen in Lateinamerika. Saarbrücken: Breitenbach.

Siñani de Willca, Tomasa (1992): "Breve biografía del fundador de la 'escuela ayllu': Un testimonio escrito sobre Avelino Siñani”. En: Educación indígena. ¿Ciudadanía o colonización? La Paz: Ed. Aruwiyiri, pp. 125-134.

Ströbele-Gregor, Juliana (1996): "Bildungsreform und indianische Bewegung in Bolivien”. En: Lateinamerika-Analysen und Berichte 13 (1996) 31, pp. 62-73.

Taylor, Solange G. (2004): "Intercultural and Bilingual Education in Bolivia: The Challenge of Ethnic Diversity and National Identity". Documento de Trabajo no. 01/2004. La Paz: Instituto de Investigaciones Socio Económicas (UCB) (<www.iisec.ucb.edu.bo/papers/2001-2005/iisec-dt-2004-01.pdf>; 04.09.2008). 
